\title{
Helix-forming Properties of Size-expanded DNA (xDNA), an Alternative Four-base Genetic Form
}

Haibo Liu, Jianmin Gao, Eric T. Kool*

Department of Chemistry, Stanford University, Stanford, CA 94305-5080

*Corresponding author. email: kool@stanford.edu

CONTENTS:

Figure S1. Thermal denaturation curves of xDNA complexes.

Figure S2. Binding stoichiometry of sequences 2 and 3 by gel shift. (p. S3)

Figure S3. Fluorescence changes for xDNAsequences 2,3,6, and 7. (p. S4)

Figure S4. Fluorescence spectrum of sequences 4 and $5 . \quad$ (p. S5)

Figure S5. CD Spectra of xDNA ss oligomers and helical complexes. (p. S6) 
A

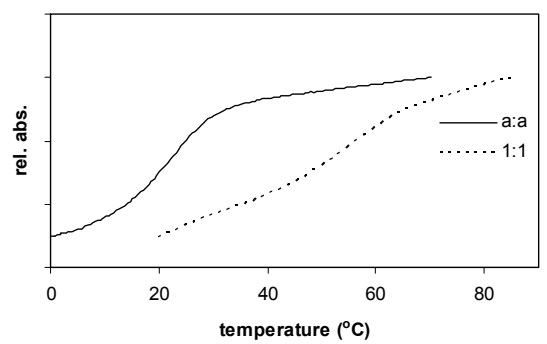

C

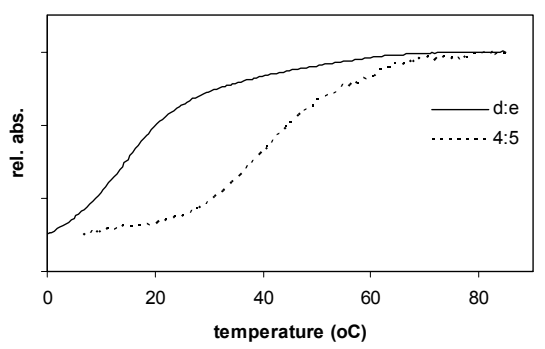

E

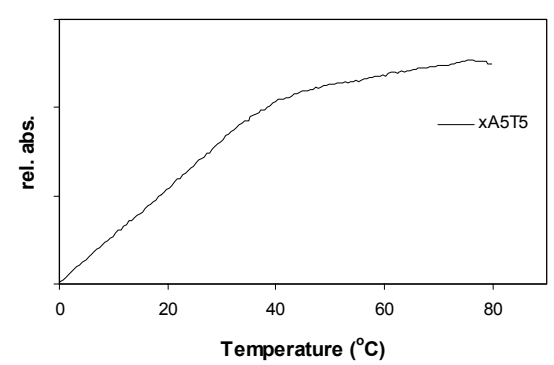

B

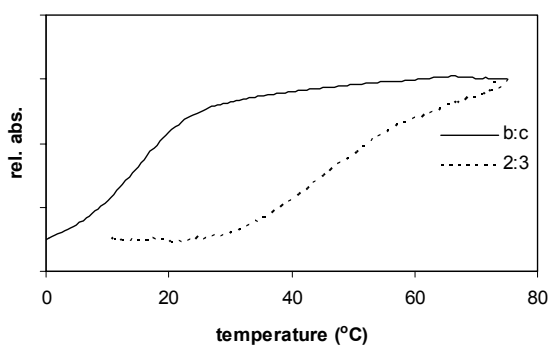

D

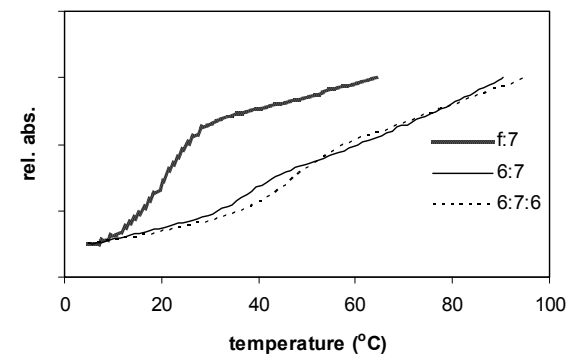

$\mathbf{F}$

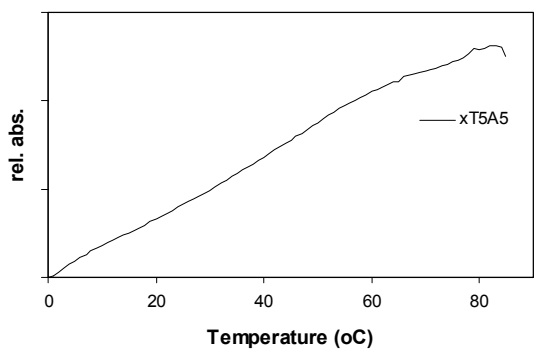

Figure S1. Thermal denaturation curves of xDNA complexes and control DNA duplexes measured at total oligomer concentration of $5.0 \mu \mathrm{M}$ in a buffer containing $10 \mathrm{mM} \mathrm{MgCl} 2,100 \mathrm{mM} \mathrm{NaCl}$, and $10 \mathrm{mM} \mathrm{Na} \cdot \mathrm{PIPES}, \mathrm{pH}$ 7.0. DNA samples were monitored at $260 \mathrm{~nm}$ and xDNA samples were monitored at $320 \mathrm{~nm}$. (A) xDNA sequence 1* and DNA sequence a. (B) xDNA sequences 2:3 and DNA sequences b:c. (C) XDNA sequences 4:5 and DNA sequences d:e. (D) xDNA duplex of 6:7 and triplex 6:7:6 and DNA duplex f:7. (E) Sequence $\mathrm{xA}_{5} \mathrm{~T}_{5}$. (F) Sequence $\mathrm{xT}_{5} \mathrm{~A}_{5}$. Curves in A-D were fit well using a two-state approximation, while complexes in $\mathrm{E}$ and $\mathrm{F}$ appeared to show non-two-state behavior.

* see Figure 1 in the manuscript for sequence numbers. 


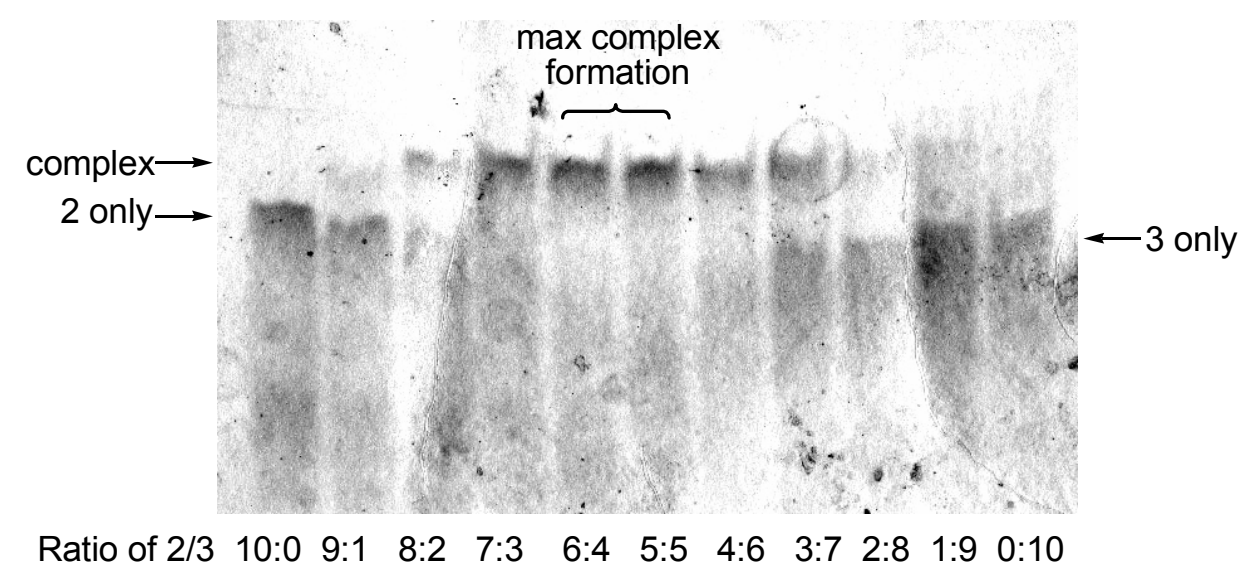

Figure S2. Binding stoichiometry of sequences $\mathbf{2}$ and $\mathbf{3}$ estimated by gel shift (20\% native polyacrylamide gel in 1x TBE buffer). Each lane was loaded with $5 \mu \mathrm{L}$ total of oligomers 2 and 3 at $200 \mu \mathrm{M}$ in the same buffer as described in Figure S1. Ratios are shown at the bottom of each lane. 

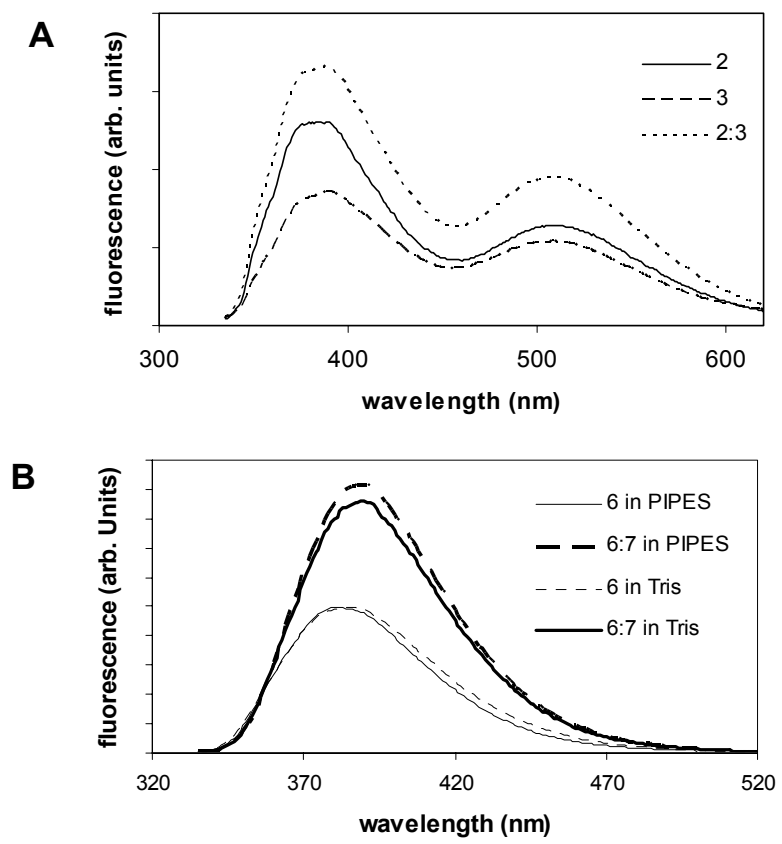

Figure S3. Fluorescence changes for xDNA. (A) Fluorescence spectra of ss $\mathbf{2}$, ss 3 and ds 2:3 excited at $320 \mathrm{~nm}$, measured in the same buffer as for $T_{m}$ studies. (B) Fluorescence spectra of ss 6, ds 6:7 in PIPES or Tris buffer excited at $320 \mathrm{~nm}$. 


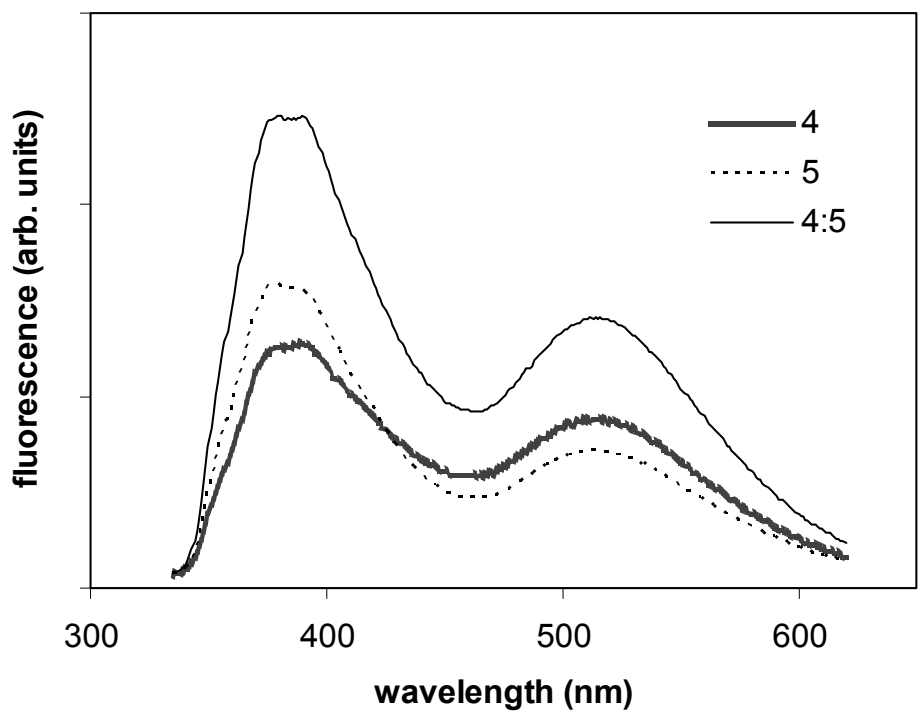

Figure S4. Fluorescence spectra excited at $320 \mathrm{~nm}$ of single strand 4, single strand 5 and duplex $4: 5$ at $5.0 \mu \mathrm{M}$ in same buffer as for $T_{m}$ measurements (see Figure 1). 

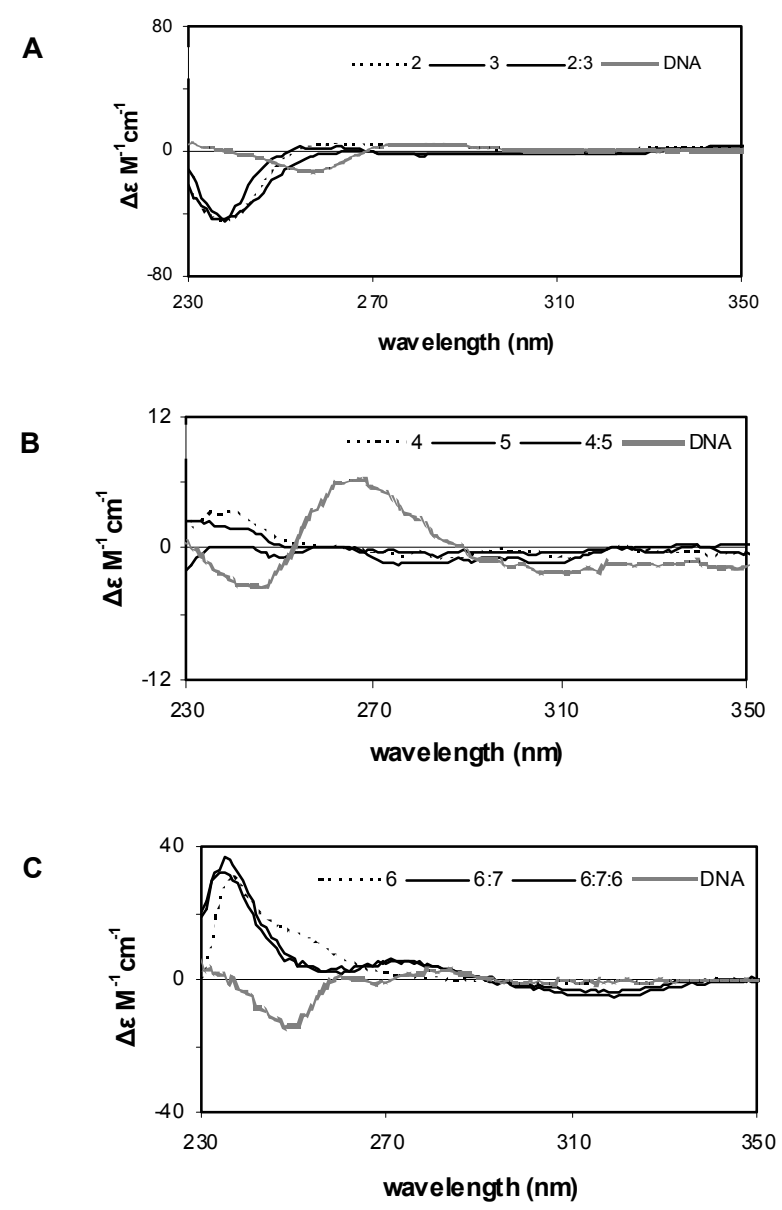

Figure S5. CD spectra of xDNA ss oligomers and helical complexes. (A) 2 and 3. (B) 4 and 5. (C) 6 and 7. Conditions: $100 \mathrm{mM} \mathrm{NaCl}, 10 \mathrm{mM} \mathrm{MgCl} 2,10$ $\mathrm{mM}$ Na·PIPES, $\mathrm{pH}=7.0,5.0 \mu \mathrm{M}$ DNA. 